\title{
ANALYSIS OF STABILITY USING AMMI AND GGE- BIPLOT METHODS IN SOME EGYPTIAN COTTON GENOTYPES
}

\author{
S.A. Shaker(1), M. A. F. Habouh(2) and A. B. A. El-Fesheikwy(1) \\ (1) Cotton research institute. Agriculture research center, Giza, Egypt. \\ (2) Faculty of Agriculture natural and resources, Aswan University.
}

Received: Feb. 14, 2019

Accepted: Feb. 27, 2019

\begin{abstract}
The Superiority of genotype must be discriminatively through multienvironment trails (MET). This study aimed to evaluation effect of genotype by environment interaction and stability performance for seven cotton genotypes over six environments via $A M M I$ and GGE-biplot methodology (genotype plus genotype by environment). Experiments were conducted using a randomized complete block design, during 2017 and 2018 seasons at six environments. Significantly affected by E, which explain $72.8 \%$ of the total variation ( $E+G+G E$ ), 5.77 for $G$. and $21.44 \%$ for GEl. The biplot analysis cleared that two environments, Beni-Souif and EL-Sharkeia with genotypes lines No.1 and 2 as the winning genotypes and the lines No. 4 and 5 as the winning in the two environments EL-Sharkeia and Kafr El-Sheikh. Lines No. 1 and 2 were the most stable the highest yielding and closest to the ideal genotypes also, line No. 4 had average stable with favorable yield, whereas line No. 5 had high average mean, but it more variable in environments. The lines No. 1, 2 and 4 were average stable according to $A M M I$ method commonly, the two lines No. 1 and 2 should be selected as the best and ideal genotypes. Also, the best environments were EL-Sharkeia and Beni-Souif.
\end{abstract}

Key words: Evaluation, Stability, AMMI, GGE- biplot, Cotton.

\section{INTRODUCTION}

A multi-environment trails (MET) are conducted for all major crops thought the world, a number of genotypes are tested in a number of environments. The select of genotype that have a wide range of adaptability is a major target for plant breeders Numerous methods for studying the behavior of genotypes in many environments by Shukla's (1972) stability variance, Eberhart and Russel's (1966) sum of squared deviation from the regression, AMMI analysis model, and from the newest method in this way the use of GGEbiplot in interpretation these points. The GGE ( genotype + genotype by environment) concept based on the understanding that genotype main effect and genotype by environment interaction are the two sources of variation that are relevant to evaluation and that they must be consider simultaneously, not alone or separately, for favorable genotype evaluation. GGE-biplot can be used to perform analysis similar to the popular the additive main effect and multiplicative interaction (AMMI) model, however, GGEbiplot remove the effect of the environment and focuses on the genotype (G) and GEI components relevant to genotype evaluation (Blanch et al 2006). Also, evaluation of genotypes performance in gunning years is better than single year data (Yan and Rajican, 2003). The biplot technique provides a powerful solution to this problem (Gabriel, 1971). The performance yield of each genotype in each environment is a measure of an environment main effect $(E)$, a genotype main effect (G), and the genotype by environment interaction (GEI) ( Yan and Kang, 2003 ).

Approximately environment source of variation explain $75 \%$ to $80 \%$ of the total yield variation. Therewith, $G$ and GEI that are relevant to genotype evaluation (Yan 2002 , Hamoud 2008 and El-Seidy et al, 2017 ). Commonly a GGE- biplot that sufficiently approximates the GGE of a 
multi-environment trails data set allows, among other things, visualization of three important aspects, (1) the genotype by environment relation as presented by the which-won-where style, which facilitate mega- environment investigation (Gauch and Zobel 1997), (2) the interrelationships among test environments, which easy identification of better environments for genotype evaluation

(Cooper et al, 1997) and redundant environments that can be dismissed (Yan and Rajcan, 2002) and (3) the interrelationships among genotypes, which facilate comparison among genotypes and genotype ranking on both mean yield and stability (Yan et al, 2001 ). The choice of genotype require to evaluate the genotypes in many environments, and selecting the genotype that possess a wide range in adaptability and stability is very important (Shaker (2013 and 2017) and El-Seidy 2017). The objective of this study were to use the GGE-biplot technique to determine the best genotype which have the best adaptation and stability over most environments and determine discriminating ability and representatives of environments.

\section{MATERIALS AND METHODS}

The evaluation of genotypes consisted of seven genotypes; five lines were advanced and two commercial cultivars, all genotypes from long staple category ( $G$. barbadense $L$,). The names of these genotypes and abbreviations are presented in Table (1). Data analysis in this study were obtained from six environments (three locations over two years 2017and 2018). Environments were Kafr El-Sheikh, EL-Sharkia and BeniSouif. At each environment, a randomized complete blocks design with three replications was used. The plot size was $13 \mathrm{~m}^{2}$ contains 5 rows, 4 meters long and $65 \mathrm{~cm}$ wide. Seed cotton yield was obtained from a yielding of a three rows from the center of each plot in each environment.

The GGE-biplot methodology, which is composed of two concepts (Gabriel 1971) and the GGE concept (Yan et al 2000) was used to visually analyze the multi-environment yield trails (MEYTs) data. The methodology uses a biplot to show the factors (genotype and genotype by environment interaction) that are also the sources of variation. In this study, genotype-focused scaling was used in visualizing for genotypic comparison with environment-focused scaling for environmental comparison.

Besides, the symmetric scaling was preferred in visualizing the which-wonwhere pattern of the MEYTs yield data (Yan, 2002).

- AMMI analysis: A BASIC computer program was written according to the method outlined by Gauch (1992), for AMMI analysis.

\section{RESULTS AND DISCUSSION}

The results of combined analysis for seed cotton yield was significantly affected by environment which explain $72.78 \%$ of the total $(G+E+G E I)$ variation, while genotype and genotype $x$ environment interaction were significant accounted for $5.77 \%$ and $21.44 \%$ respectively (Table 2) and showed the effect of changes in environments on the yield performance of the genotypes evaluated. Dehaghani et al. (2006), Hamoud (2008) and El-Seidy et al. (2017). Gauch and Zobel (1997) reported that normal multi-environment yield trails (MEYT), environment accounted for about $80 \%$ of the total variation while $G$ and GEI each account for approximately 10\% Sadabadi, et al (2018) reported that GGE-biplot method showed that the firs two principal components regression model explain $74 \%$ of the observed changes Also, its graph plotted reflect the superior some genotypes. A large 
sum of squares for environment cleared that the environments were variously with large difference among environmental means causing because of the variation in seed cotton yield. The quantum of the GEI sum of squares was 1.63 times larger than for genotypes cleared that there was a large difference in genotypic response across environments. Mora et al. (2007) reported a high important of the genotype by environment interaction. Campdell and Jones (2005) reported the importance of application direct analysis of GEI as they related to genotype performance and classification of testing environments.
The GGE-biplot model account for $78.1 \%$ of the total variation of the standardized data contain of $50.4 \%$ and $27.7 \%$ variance attributable to the first (PC1) and second (PC2) principle component respectively. The relatively percentage $(21.44 \%)$ of variance for GEI reflects the complexity of the relationship among genotypes and the environment. El-Shaarawy et al. (2007) and Hamoud (2008) reported that the source of variation of seed cotton yield for IPCA1 and IPCA2 were (38.55\% or $38.8 \%)$ and $34.59 \%$ or $30.2 \%$, respectively.

Table (1): The mean performance (Kentar per Feddan) for the seven cotton genotypes across six environments .

\begin{tabular}{|c|c|c|c|c|c|c|c|}
\hline & & \multicolumn{2}{|c|}{ Kafr El- Sheikh } & \multicolumn{2}{c|}{ Sharkia } & \multicolumn{2}{c|}{ Beni- Souif } \\
\cline { 3 - 8 } Name & Abbreviation & 2017 & 2018 & 2017 & 2018 & 2017 & 2018 \\
\hline Danara x Giza 85 & Line 1 (L1) & 10.28 & 11.48 & 9.22 & 11.81 & 12.89 & 9.57 \\
\hline Danara x Giza 85 & Line 2 (L2) & 9.94 & 11.13 & 8.47 & 12.10 & 12.76 & 9.48 \\
\hline Danara x Giza 85 & Line 3 (L3) & 8.90 & 11.78 & 7.41 & 11.48 & 11.53 & 7.80 \\
\hline Danara x Giza 85 & Line 4 (L4) & 9.06 & 9.87 & 8.75 & 11.63 & 12.41 & 8.38 \\
\hline Danara x Giza 85 & Line 5 (L5) & 9.19 & 12.51 & 9.27 & 12.66 & 12.92 & 8.64 \\
\hline Giza 90 & G. 90 & 12.10 & 10.50 & 8.12 & 11.03 & 10.54 & 8.32 \\
\hline Giza 95 & G. 95 & 11.68 & 9.14 & 8.03 & 10.42 & 13.18 & 8.53 \\
\hline
\end{tabular}

Table (2): Combined analysis of variance for yield of seven genotypes across six environments .

\begin{tabular}{|c|c|c|c|c|}
\hline S O V & DF & SS & MS & SS\% \\
\hline E & 5 & 254.4752 & $50.895^{\star *}$ & 72.78 \\
\hline Block / E & 12 & 27.3841 & 2.282 & \\
\hline G & 6 & 20.1781 & $3.363^{\star *}$ & 5.77 \\
\hline E*G & 30 & 74.9746 & $2.4992^{\star *}$ & 21.44 \\
\hline IPCA1 & 10 & 48.551 & $4.855^{\star *}$ & 71.68 \\
\hline IPCA2 & 8 & 19.178 & $2.397^{*}$ & 28.32 \\
\hline IPCA residual & 12 & 7.273 & 0.603 & \\
\hline Error & 72 & 69.8141 & 0.9696 & \\
\hline
\end{tabular}


Which-won-where or which-is-best for what analysis.

Studying the which-won-where pattern of multi environment yield trails is important for the possible existence of different mega-environment in a region (Yan et al, 2000 and 2001). The polygon view a biplot is the best way to visualize the interaction patterns between genotypes and environments and to effectively interpret a biplot (Yan and Kang, 2003). With respect to (Fig. 1) the rays divided the biplot into 5 sectors and the environments fail into 3 of them. A good feature of this view of GGE-biplot is that the top genotypes for each sector has higher yield than the others in all environments that all fall in the sector, (Yan 2002). Three environments, $Y_{1} L_{2}$, $Y_{1} L_{3}$ and $Y_{2} L_{3}$ fall into sector 1 delineated by ray 1 and 2 and the vertex genotypes for this sector were line 1 and line 2 suggesting that these genotypes were high yielding for these environments. Similarly, two environments $Y_{2} L 1$ and $Y_{2} L_{2}$ fall into sector 2 delineated by rays 2 and 3 and the vertex genotypes for this sector was line 4 cleared that this genotype was the higher yielding for these two environments. Also, Giza 95 fall into sector 5 high yielding at $Y_{1} L_{1}$ environment. Genotypes located near the plot origin were less responsive than the vertex genotypes for example line 1 , line 2 and line 4. The lines 1, 2 and 4 recorded the highest average yield (large PC1 scores), but the genotypes line 3, Giza 90 and Giza 95 were below average (PC1 scores $<0$ ). The biplot showed not only the average yield of genotype (PCA 1 effects), but also how it is achieved, (Kaya et al, 2006).

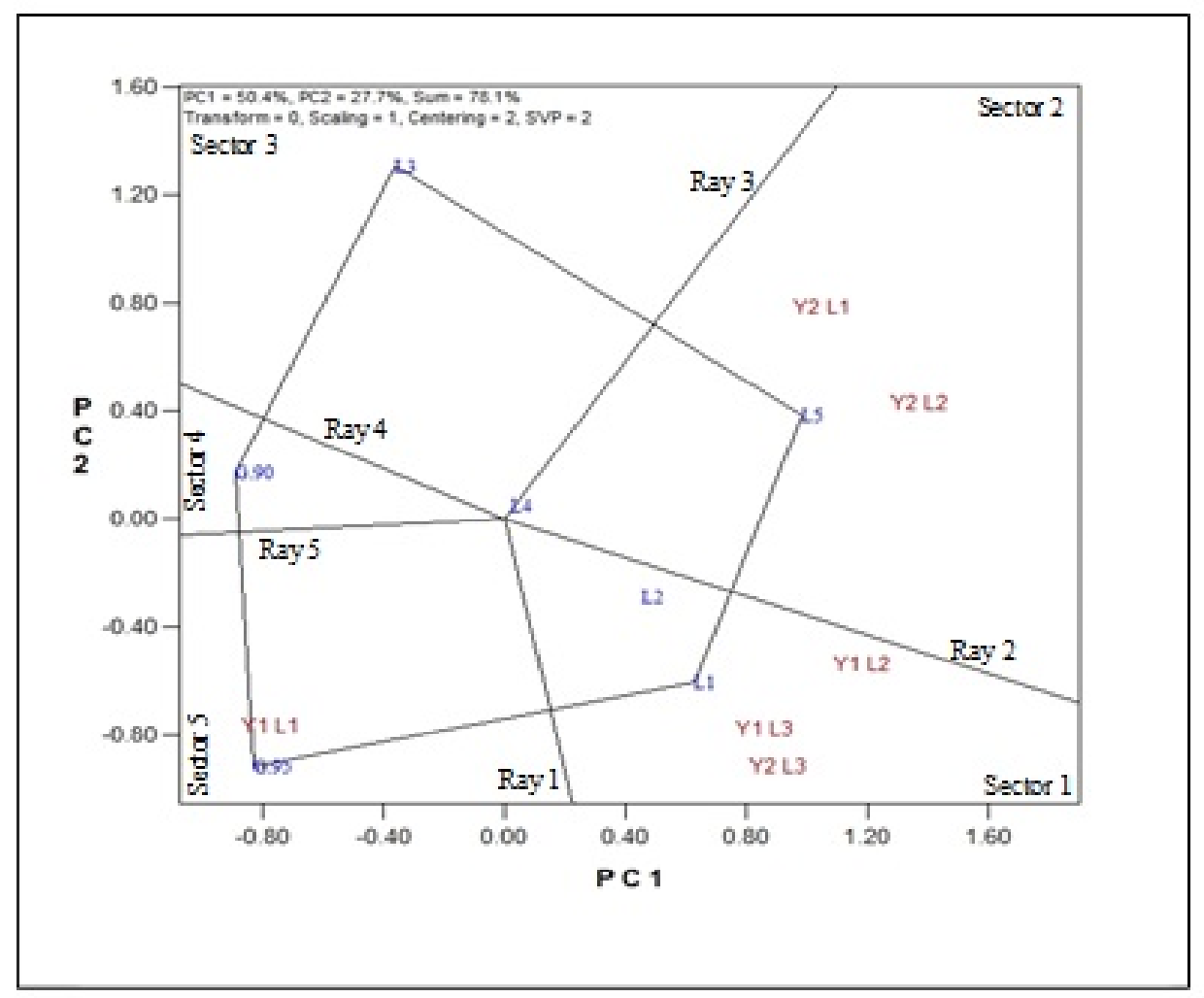

Figure 1 . Polygon view of the GGE-biplot for the which - one - where paltern for genotypes and environments. 
Top genotypes without any environments in their sectors were not the highest yielding genotypes at any environments. Morever, they were the poorest at all on some environments. In addition, from this figure the GGE-biplot allows to evaluate genotypes for their yielding ability and stability and to evaluate environments for their discriminating ability (Otoo and Asiedu, 2006). The lines 1, 2 and 4 recorded high average yield (largely primary scores) and was relatively stable over environments (small absolute secondary scores). Also, the line 4 was above the average $\mathrm{PC1}>0$ and also relatively stable. In contrast the check variety Giza 95 was unstable and poor yielder in environment because they small primary scores (low yielding) and most unstable (large secondary scores).
Yield performance and stability of genotypes.

The genotypes evaluated by an average environment coordination (AEC) method, on average environment is defined by the average PC1 and PC2 scores of all environments, represented by a small circle (Figure 2). A line was then drawn to pass through this average environments and biplot origin This average environment axis serves as the abscissa of the AEC. The ordinate of the AEC is the line that passes through the origin and the direction away from the biplot origin indicates greater GEI effect and reduced stability. The AEC ordinate separates genotypes with below average means from those with above average means.

Table (2) showed that, the lines No 1, 2 and 5 recorded high yield above average means Also, line No. 4 recorded high yield while line no 3 recorded below average means.

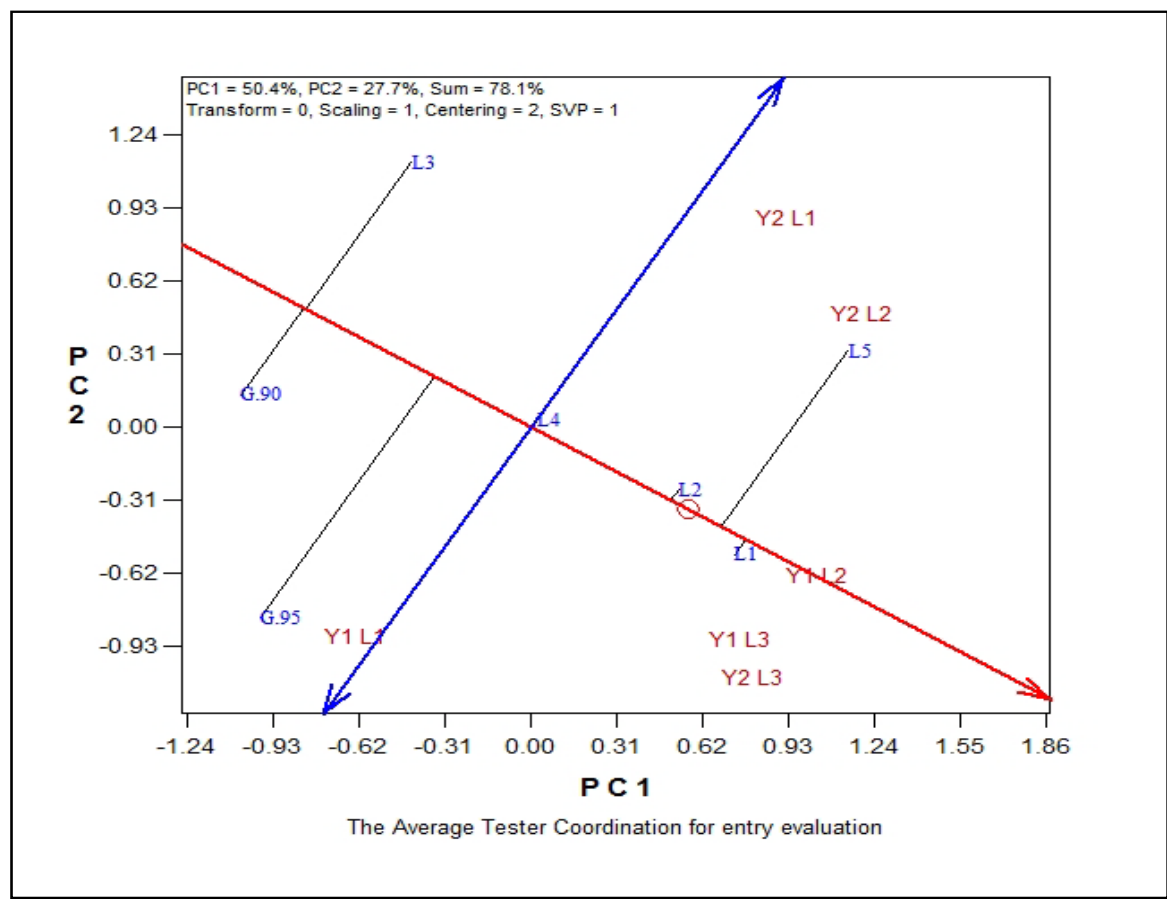


S.A. Shaker, et al.,

Figure 2. Avrage environment coordination (AEC) view of the GGE-biplot for the means performance and stability of genotypes.

With respect to (Fig. 2) the length of the average environment vector was sufficient to select genotypes based on yield mean performance. So, the lines 1 , 2 and 4 could be selected while the rest may be cancel. Also, a longer projection to the average environment all coordination (AEC) (Fig. 2). Regardless of the direction, represents a greater of the GEI genotypes which indicates that it is more variable and less stable across environments or vice versa. The same results is obvious from estimates of AMMI analysis, the biplot and IPCA1 and IPCA2 scores are presented in (Fig. 6). Genotype that located around the origin have the minimum interaction so, three lines no 1, 2 and 4 were located around the origin. These lines are the most stable for seed cotton yield, These results are in agreement with those reported by El-saarawy et al. (2007) and Shaker (2017). In the same time, line No. 5 recorded the highest yield and longer projection to the AEC ordinate so, it is more variable.

\section{Ideal genotypes analysis.}

Ideal genotypes concept of GGE biplot clear that the closer genotypes located relative to the ideal genotypes in the (Fig. 3). In addition, using ideal genotypes as the central concentric circles were drawn to help envision the distance between each genotype and the ideal genotype because the units of both PC1 and PC2 for the genotypes are the original unit of yield in the genotype focused scaling (Fig. 3). Consider of the ranking of the genotypes, using the ideal genotype understandable of GGE-biplot, line no 1 was the best genotype which was into the circle center, followed by line 2 which located in the second circle, followed by lines no 4 and 5 . While, genotypes line 3, Giza 90 and Giza 95 were located far from the ideal genotype. These results are in agreement with those reported by AbouZahra, et al. (1988).

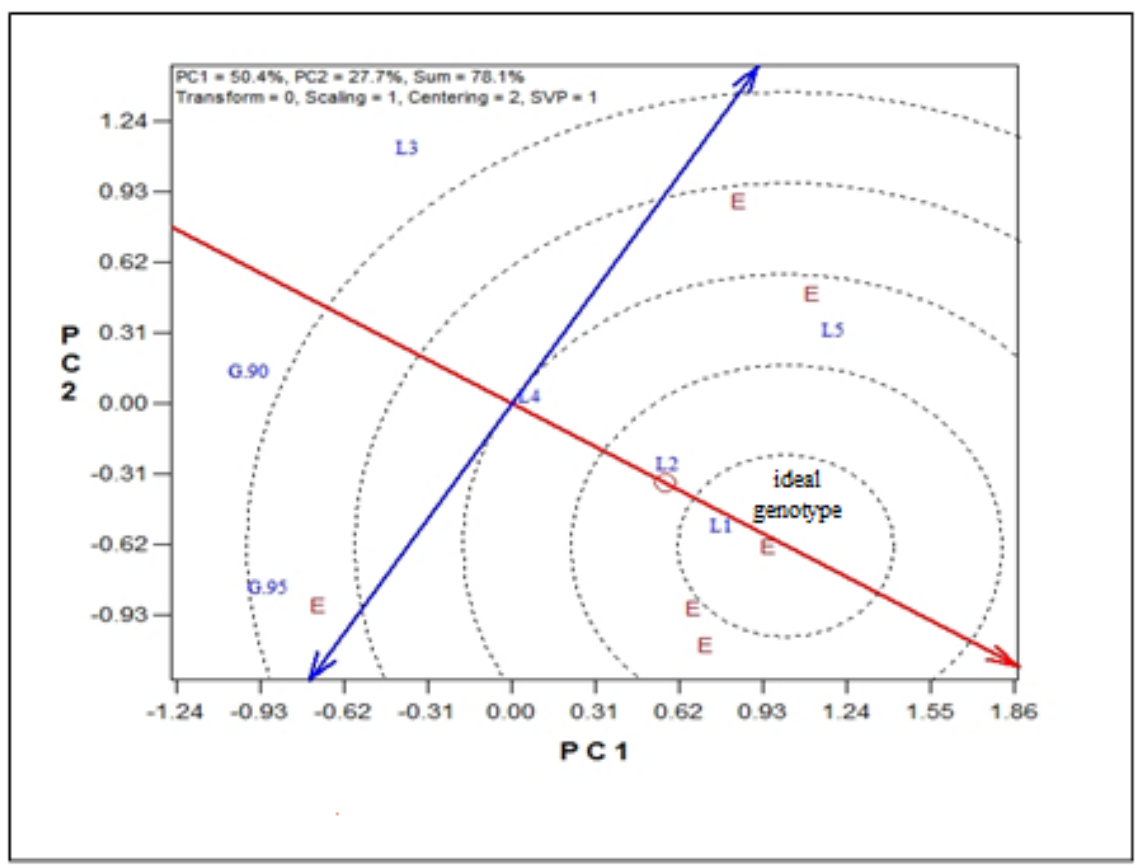


Figure 3. Ranking of genotypes based on both mean and stability refers to ideal genotypes.

\section{Relationships among environments and genotypes}

If the data is sufficiently approximate by the biplot will the cosine of the angle between the vectors of two testers (environments) approximates the correlation coefficient between them. Also, if the biplot explains a large portion of the total variation more than $50 \%$ (78.1\% in this case), the angles exactly shows the correlations among the entries (genotypes). Two environments or two genotypes are positively correlated when the angle between their vector is $<90$ a degree while they are negatively correlated when the angle is $>90$ a degree. Two genotypes are independent if the angle between them is 90 a degree. Zero means, correlation coefficient $r=1$ and 180 degrees means $r=-1$. Environment with longer vectors are more discriminative of the genotypes but it short vectors are less discriminating and these located at the biplot origin are not discriminating. The test environment as showed in (Fig. 4) at Kafr El-Shiekh and Beni-souif over two years were most discriminating as indicated by the longest distance between its marker and the origin. These results maybe, due to its large PC2 score. EL- Sharkia location over two years were not the most discriminating, therefore genotypic differences should be highly stable with those average over environments, for it had near zero PC2 scores compared to the others. Relation among the environments are presented in (Fig. 5). The angles among the vectors of Benisouif and EL- Sharkia locations over two years also among them (Y1L3, Y2L3, Y1L2 and Y2L2) were all acute less than 90 degree cleared that they are positively correlated, while the angles among the vectors of Beni-Souif and Kafr El-Shiekh over two years were equal 90 degree, therefore they are independent.

Relationships among the genotypes are presented in (Fig. 6) which the angles among the vectors of lines No 1, 2, 4 and 5 were all acute less than 90 degree, cleared that they are positively correlated. While, the line no 3 was not correlated or negatively correlated among the previous lines because the angles among them were equal 90 degree or $>\mathbf{9 0}$ degree, respectively.

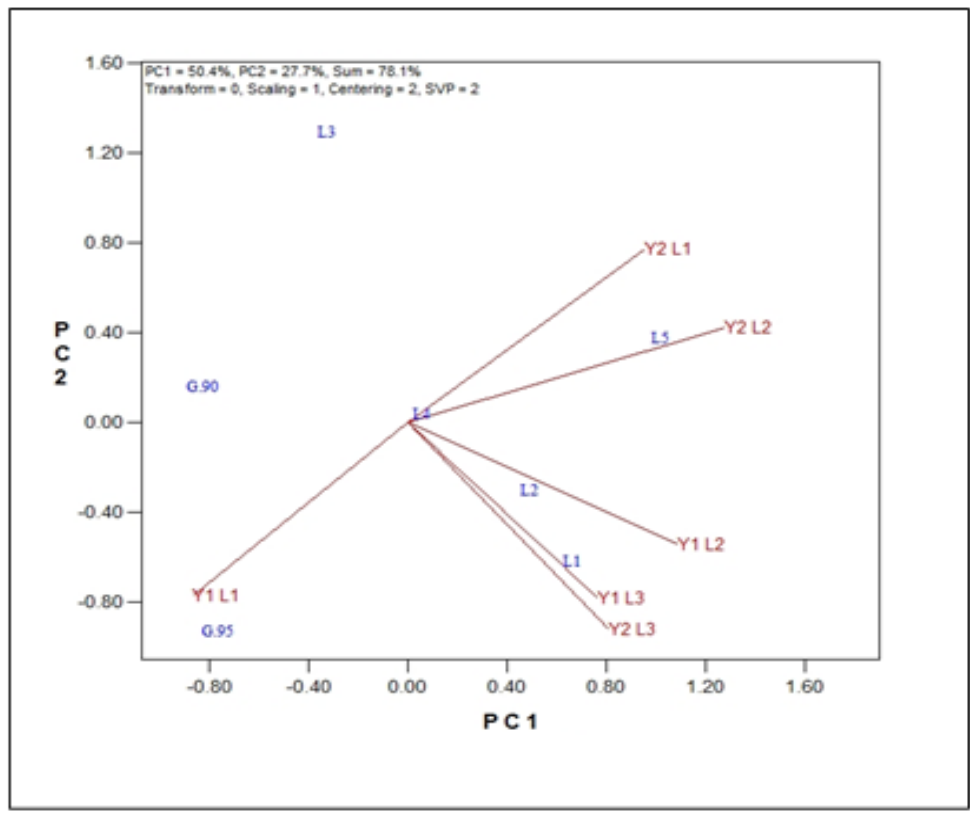


Figure 4. Biplot of relationships among six environments.

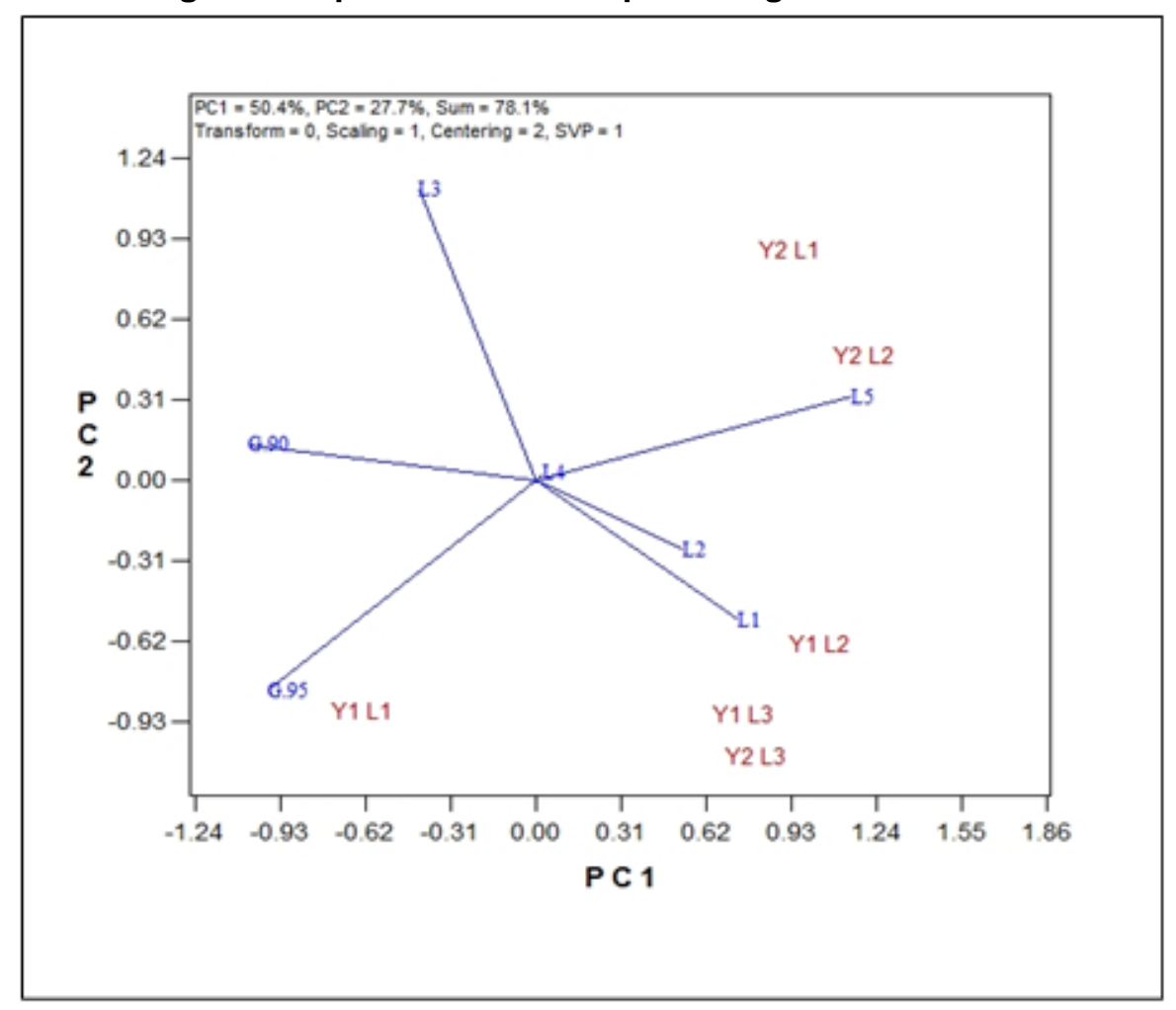

Figure 5. Biplot of relationships among seven genotypes in six environments.

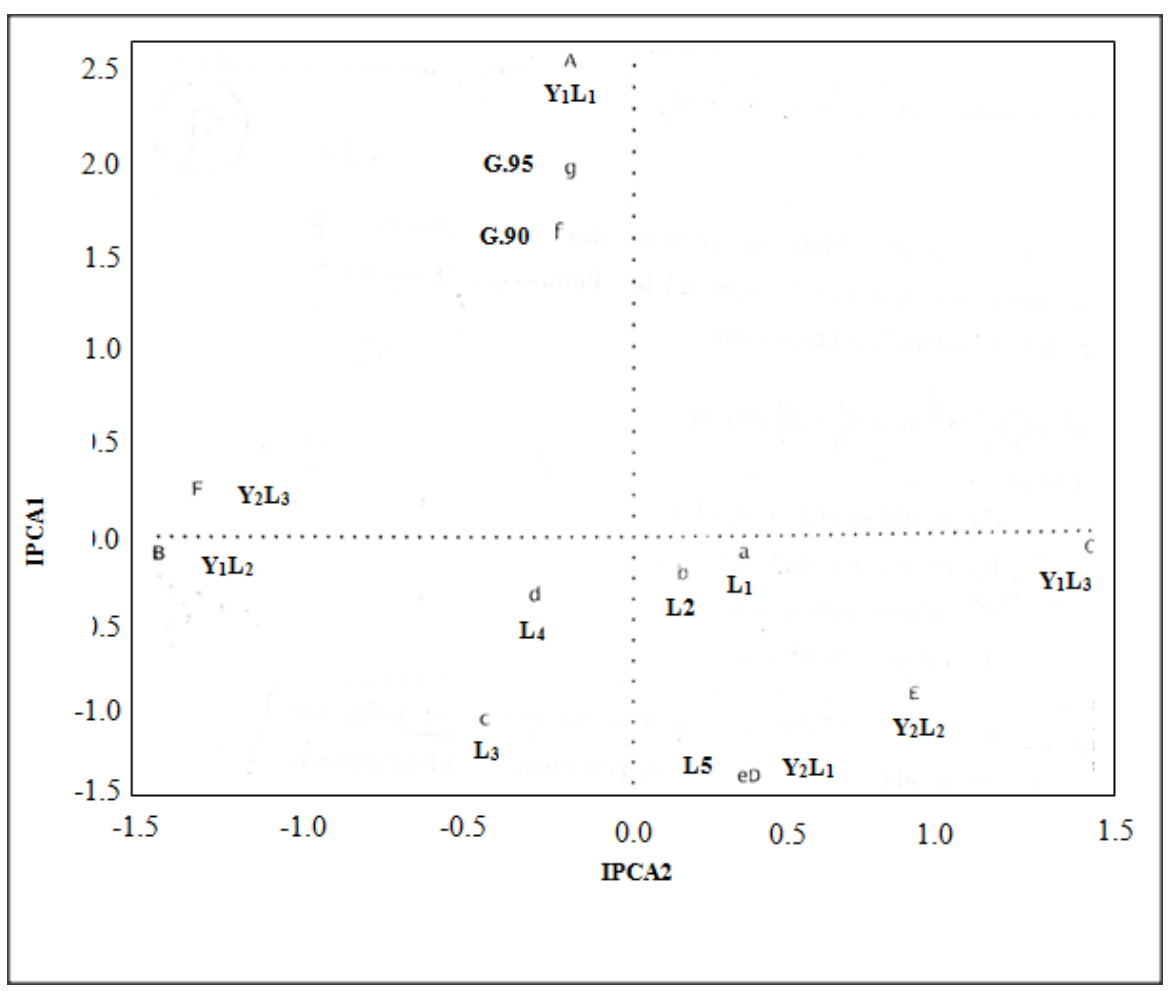


Figure 6. AMMI biplot for IPCA1 and IPCA2 scores for seed cotton yield of seven genotypes grown at six environments (from $A$ to $F$ ).

Positively correlated among the commercial cultivars Giza 90 and Giza 95 also, between Giza 90 and the line No. 3 (the angle between vectors less than 90 degree). Negatively correlated among the lines No. 1, 2, 4 and 5 and the other genotypes (the angles between the vectors $>90$ degree.

\section{Conclusion}

Commonly, results showed that the seven genotypes studied at the six environments can be canceled to four genotypes according to their performance and stability analysis lines No .1, 2, 4 and 5 to reflect the performance of all the genotypes. In the same time EL-Sharkia location is the best environment.

\section{REFERENCES}

Abou-Zahra, S. I. S., H. Y. Awad and S. A. El-Shaarawy (1998). Analysis of genotypic stability in some Egyptian cotton genotypes under different locations. Res. Rev., 67 (5):679-686.

Blanch, S. B., G. O. Myers, J. Z. Zumba, D. Caldweel and J. Hayes (2006). Stability comparison between conventional and near-isogenic transgenic cotton cultivars. The Journal of cotton Sience 10:17-28.

Cambdell, B. T. and M. A. Jones (2005). assessment of genotype $x$ environment interactions for yield and fiber quality in cotton performance trails. Euphytica ,144:69-78.

Cooper, M., R. E.Stucker, I. H. Delacy and B. D. Harch (1997). Wheat breeding nurseries, target environment, and indirect selection for grain yield. Crop Sci., 37:1168-1176.

Dehaghani, H., A. Ebadi and A. Yousefi (2006). Biplot analysis of genotype by environment interaction for Barly yield in Iran. J. 98: 388-393.
Eberhart, S.A. and W.A. Russell (1966). Stability parameters for comparing varieties. Crop Sci. 6: 36-40.

El-Seidy, E. H, S. A. Shaker and Hanan A. E. El-Ganayny (2017). Evaluation of some Egyptian cotton cultivars for yield constancy and adaptability. J. plant production, Mansoura Univ., 8 (2): 205 - 210.

El-Shaarawy, S. A. A., M. R. Abd El-Bary, H. M. E. Hamoud and W. M. B. Yehia (2007). Use of the highly efficient AMMI method to evaluate new Egyptian cotton genotypes for performance stability. World cotton Res. Con. 4 In press.

Gabriel, K. R. (1971). The biplot graphic display of matrices with application to principal component analysis. Biometrika 58: 453-467.

Gauch, H. G. (1992). Statical analysis of regional yield traits. AMMI analysis of factorial design. Elsevier science publishers B. V. Amsterdam - London - New York - Tokyo.

Gauch, H. G. and R. W. Zobel (1997). Identifying mega-environments and targeting genotypes. Crop Sci. 37: 311-326.

Hamoud, H. M. E. (2008). Studies on genotype $X$ environment interaction using GGE-Biplot analysis for seed cotton yield in delta region of Egypt. Egypt. J. Agric. Res, 86 (6): 23512364.

Kaya, y., y. Akcura and S. Taner (2006). GGE Biplot analysis of multienvironment yield trails in bread wheat. Turk J. Agric .30:325-337.

Mora, F., O. F. Junior and C. A. Scapium (2007). Prediction of cultivar effects on cotton yield in the presence of genotype-environment interaction. Cient Inv. Agr. 34 (1): 7-16. 
Otoo, E. and R. Asiedu (2006). Cultivar evaluation and mega-environment investigation of Dioscorea cayenensis cultivars in Ghana based on the GGE biplot analysis. Journal of food Agriculture \& Environmental 4: 162166.

Sadabadi, M. Fathi, G. A. Ranjbar, M. R. Zangi, S. K. Kazemi Tabar and $H$. Najafi Zarini (2018). Analysis of stability and adaptation of cotton genotypes using GGE biplot method. Trakia J. Of sciences 16 (1): 51 - 61 .

Shukla's G.K. (1977). Some statistical aspects of partitioning genotype environmental components of variability. Heredity, 29: 237-245

Shaker, S. A. (2013). Evaluation and stability parameters of some Egyptian long staple cotton genotypes. Egypt. J. plant breed. 17 (2): 390 - 406. Special Issue.

Shaker S. A. (2017). Evaluation and stability analysis of Egyptian cotton cultivars. Egypt. J. plant breed. 21 (5): $665-683$.
Yan, W. (2002). Singular-value portioning biplot analysis of multi- environment trail data. Agron. J. 94: 990-996.

Yan, W. and I. Rajcan (2002). Biplot evaluation of test sites and trait relations of soybean in Ontario. Crop Sci. 42 (1): 11-20.

Yan, W. and I. Rajcan (2003). Prediction of cultivar performance based on single vs. multiple year trials. Crop Sci. 43:449-455.

Yan, W., L. A. Hunt, Q. Sheng and Z. Szlavnics (2000). Cultivar evaluation and mega-environment investigation based on GGE biplot. Crop Sci. 40 (3): 597-605.

Yan, W. and M. S. Kang (2003). GGE biplot analysis A graphical tool for breeders, geneticists and agronomists CRC Press, Boca Rotation, FL.

Yan, W., Q. Sheng, Y. G. Hu and L. A. Hunt (2001). GGE biplot an ideal method for graphical analysis of genotype by environment interaction. Acta Agronomica Sinica 27: 21-28. 
تحليل الثبات بأستخدام طريقتي AMMI والمحاور الثنائية لبعض التراكيب الوراثية من القطن المصري

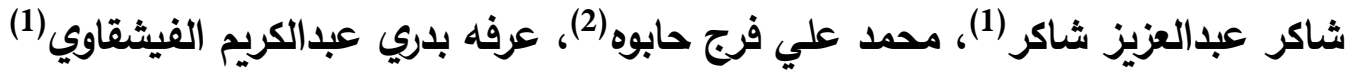

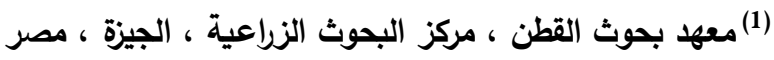

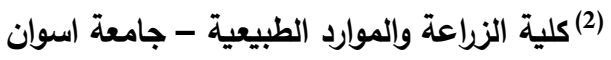

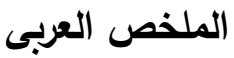

تقيييم التراكيب الوراثية في عدة بيئات ( مناطق ) عملية هامة للمربي والمنتج للتعرف علي التراكيب الوراثية المتفوقة

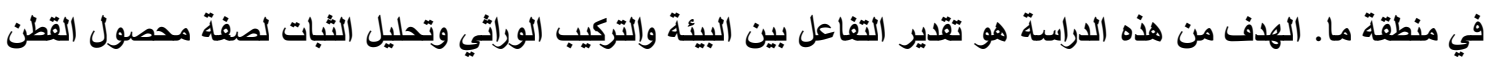

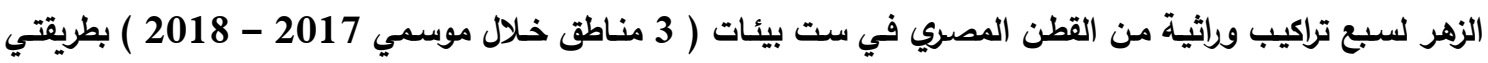
والمحاور الثنائية للتفاعل بين البيئة والتركيب الوراثي ( AMMI

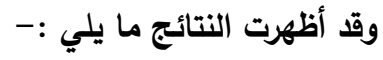
• كان التباين البيئي 72,78\% بالنسبة لمجموع تباينات البيئة ، التركيب الوراثي وتفاعل البيئة مـع التراكيب الوراثية.

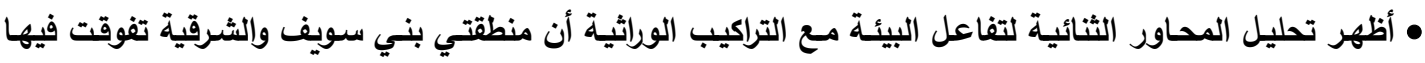

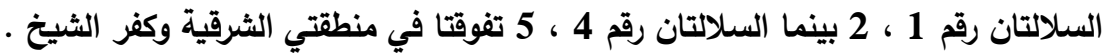

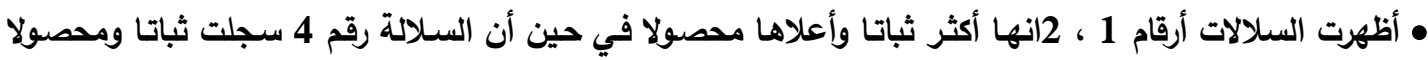

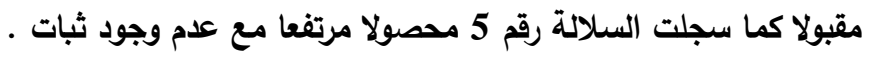
• • تعتبر السلالات أرقام 1 ، 2 الأقرب للتركيب الوراثي الأمثل .

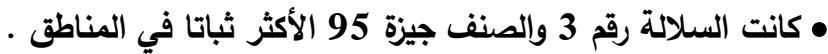
• بدراسة درجة القرابة بين التركيب الوراثية يمكن انتخاب السلالات 1 ، 2 ، 4 كأفضل التراكيب التاكئ الوراثية وبالنسبة

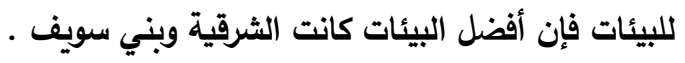

\footnotetext{
كلية الزراعة - جامعة طنطا

أسماء السمادة المحكمين

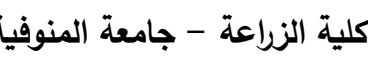

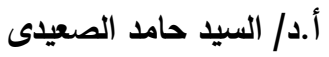

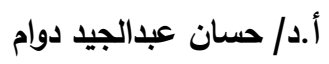


S.A. Shaker, et al., 